A N N A L E S Annales de Bretagne et des Pays de l'Ouest

119-1 | 2012

Varia

\title{
Arthur Regnault, architecte (1839-1932). La quintessence de l'art sacré
}

\section{Patrick Harismendy}

\section{(2) OpenEdition}

9 Journals

\section{Édition électronique}

URL : http://journals.openedition.org/abpo/2359

DOI : $10.4000 / a b p o .2359$

ISBN : 978-2-7535-1852-0

ISSN : 2108-6443

\section{Éditeur}

Presses universitaires de Rennes

Édition imprimée

Date de publication : 30 mars 2012

Pagination : 215-216

ISBN : 978-2-7535-1850-6

ISSN : 0399-0826

\section{Référence électronique}

Patrick Harismendy, «Arthur Regnault, architecte (1839-1932). La quintessence de l'art sacré », Annales de Bretagne et des Pays de l'Ouest [En ligne], 119-1 | 2012, mis en ligne le, consulté le 10 décembre 2020. URL : http://journals.openedition.org/abpo/2359; DOI : https://doi.org/10.4000/abpo.2359

Ce document a été généré automatiquement le 10 décembre 2020.

(c) Presses universitaires de Rennes 


\title{
Arthur Regnault, architecte (1839-1932). La quintessence de l'art sacré
}

\author{
Patrick Harismendy
}

\section{RÉFÉRENCE}

Jean-Yves Andrieux (dir.), Arthur Regnault, architecte (1839-1932). La quintessence de l'art sacré, Rennes, PUR/Archives départementales d'Ille-et-Vilaine, 2011, 255 p. (ISBN 978-2-7535-1380-8; 978-2-86035-024-2).

1 Catalogue de l'exposition « Arthur Regnault, architecte-voyageur » qui s'est tenue aux archives départementales d'Ille-et-Vilaine de juin à septembre 2011, ce très bel ouvrage relié est abondamment illustré grâce aux fonds des archives (présentés p. 80-81 et 198-205) que complètent avec bonheur des sources privées. Vingt-deux auteurs y ont contribué. L'intérêt majeur ici, après les travaux de Nadine-Josette Chaline ou de JeanMichel Leniaud sur les églises du $\mathrm{XIX}^{\mathrm{e}}$ siècle, est de pouvoir suivre un seul individu mais atypique, dans toute sa diversité créatrice. Pour cela la matière se distribue essentiellement en deux grands ensembles. Les première, seconde et quatrième parties $\mathrm{du}$ volume portent sur le contexte, l'œuvre globale et l'écho tant en France qu'à l'étranger des travaux de Regnault. Le troisième et le dernier volet sont constitués de huit monographies détaillées, relatives à sept églises et un manoir (Château-Létard), et d'un catalogue avec photos et notices répertoriant les édifices religieux bâtis par Regnault ou sur lesquels il est intervenu, avant tout en Ille-et-Vilaine : soit 71 églises paroissiales, deux chapelles et une collégiale... Chiffres considérables donc, même si l'heure est alors aux grands chantiers en ce demi-siècle de très hautes eaux religieuses et qu'au surplus en Ille-et-Vilaine on a beaucoup plus démoli et reconstruit que partout ailleurs en Bretagne (Bernard Heudré). Et de manière très provisoire - car Regnault luimême entretint le mythe de n'avoir bâti que des églises -, on peut ajouter la construction d'une dizaine de châteaux, la restauration ou la reprise d'autant (dans l'Ouest), l'édification d'une douzaine de maisons ou d'hôtels particuliers (surtout à Rennes), de dizaines d'écoles catholiques (Jean-Marie Laloy ayant le monopole des 
écoles publiques), l'installation de centaines de cheminées ornementales dans des maisons (Roger Blot, Jean-Yves Andrieux).

Fils d'un médecin de Bain-de-Bretagne, bachelier à seize ans, centralien à vingt, Regnault entre en architecture après deux années passées comme ingénieurconstructeur, comme son frère aîné devient médecin et son cadet prêtre. Avec méticulosité. Douze carnets de voyage (1862 à 1882), deux agendas (1865 et 1869), des Notes autobiographiques au soir de la vie disent un observateur scrupuleux des objets architecturaux rencontrés au fil des voyages en Italie ou en France, et ainsi décrits, croqués, appréciés. En procède un réservoir de formes dans lequel Regnault puise sa vie durant (Pascale Tumoine). La carrière de près de soixante ans (de 1865, un an avant l'installation définitive à Rennes, à 1929) est à l'identique dans la quête du sérieux où s'entremêlent chantiers privés et commandes d'églises (J.-Y. Andrieux). Mais l'écriture n'est pas asservie à un registre unique, source de redites. Chrétien fervent, auditeur, puis animateur de la conférence de Saint-Vincent-de-Paul, à Rennes, l'architecte, proche par l'esprit de Lacordaire et Montalembert, assimile les leçons graphiques de Viollet-le-Duc, écoute celles du chanoine Brune, directeur du grand séminaire de Rennes et curé-architecte lui-même, dévore les manuels de ses contemporains comme celui d'Anatole de Baudot, s'enthousiasme des hardiesses d'Abadie pour le Sacré-Cœur, et consulte ce dernier pour l'église néo-byzantine de Corps-Nuds - sans le suivre! mais sait rester lui-même. Ces inspirations méthodiques contribuent au final à une très grande variété dans les formes et les rythmes, venant ainsi abonder un goût de l'expérimentation peu banal. Les auteurs repèrent, simultanément, jusqu'à huit styles pour les constructions en neuf, sans compter les restaurations ou extensions, elles aussi propices à des interventions majeures et inspirées d'une forte culture visuelle telle la veine finistérienne appliquée à plusieurs clochers comme celui de Saint-Pierre de Chelun (Philippe Bonnet, Sabrina Dalibar). Par ailleurs souvent spectaculaires, ses constructions sont tout sauf des "placages» paysagers ou culturels. L'existant est souligné (les retables notamment, mis en valeur), la création toujours adaptée aux fidèles: à leurs souhaits comme à leurs ressources que renforce le recours aux matériaux locaux et à un calcul au plus juste des dépenses autorisées par l'administration concordataire qui dispose depuis les années 1850 d'une grille très fine en la matière (Grégory Robert). Goût de l'économie, sens presque acharné de l'effort, attention aux sensibilités dessinent ainsi une vie professionnelle et privée en parfaite concordance. Soumis à des commanditaires ayant des idées souvent très arrêtées, Regnault s'en affranchit d'évidence lorsque, sa réputation aidant, il compose à l'envi. Dans les faits et dès les années 1875, les églises enchevêtrent les styles jusqu'à l'extravagance de Noyal-sur-Vilaine, Lohéac ou Saint-Senoux, justifiant l'éclectisme (Philippe Bonnet). Doté d'un sens peu commun pour capter l'esprit des lieux, l'architecte réemploie des matériaux déconstruits, restaure ce qui peut l'être, et accorde aux détails, qu'il s'agisse de la pierre, du bois, de la peinture ou du mobilier, un traitement sourcilleux (R. Blot, Denis Chambet). On mesure là sa capacité à appréhender les chantiers dans leur totalité en intégrant aussi bien les legs archéologiques, les avancées érudites et les nouveaux matériaux mis à sa disposition (Vincent Jouve). Enfin, cet architecte breton sut s'exporter, notamment dans le très catholique Canada (Luc Noppen), la « filière » eudiste le requérant pour quatre édifices au Québec, en Nouvelle-Écosse et dans le Nouveau-Brunswick. Un regret peut-être en forme d'invite à la poursuite de l'enquête: plusieurs chantiers sont très bien documentés dans le processus constructif et financier; en revanche, abstraction faite 
de la maison Brunet, on sait très peu de chose - comme très souvent - des entreprises ou des artisans qui ont accompagné Regnault dans sa carrière. Ce n'est évidemment pas secondaire pour un tel pourvoyeur d'emplois. 